\title{
Teaching European Studies: A Blended Learning Approach
}

\author{
http://dx.doi.org/10.3991/ijet.v6i4.1770 \\ A. Christova and A. Mihai \\ Vrije Universiteit Brussel (VUB), Brussels, Belgium
}

\begin{abstract}
This paper will be looking into the teaching method developed by the Institute for European Studies in Brussels, combining an e-learning tool- the E-modules- with face-to-face training sessions and webinars. The main aim is to analyse the three different components of this "blended learning" pedagogical approach, as well as the way they complement each other and to address a few of the challenges that have emerged from the experience of working with them so far. The E-modules are an e-learning platform that has been designed with the purpose of offering a structured and interactive way of learning how the European Union functions. The face-to-face training component currently takes the form of three days in-house seminars, covering in an intensive manner the most important areas of the curriculum. The lectures are held by a mix of academics and practitioners, hereby ensuring a balanced approach, in which theory and practice come together to facilitate the learning experience. The third element of the "blended learning" method is placed in-between online and face-toface learning: interactive seminars and debates are held online, giving the participants the chance to deepen their knowledge in certain fields of interest and to discuss the content of the course with specialists and among themselves. The mixture of delivery and interaction methods was chosen in order to accommodate a large variety of target groups, ranging from students to professionals working with EUrelated issues, with different backgrounds and geographical origins. One of the main challenges is to use each medium for the functionalities it is best designed for and to ensure that the various pieces of the pedagogical puzzle fit together perfectly, while allowing the learners the flexibility that had initially directed them towards "blended learning" instead of a classical classroom approach.
\end{abstract}

Index Terms-Blended learning, e-learning, social sciences, European studies, webinars

\section{The ConteXt: Blended LEARNING AND SOCIAL SCIENCE}

Blended learning has become throughout the last decade one of the learning approaches embraced by many Higher Education institutions. The reason for its increased use can be found in the very nature of this pedagogical approach: "blended learning is the effective combination of different modes of delivery, models of teaching and styles of learning" [1]. Various definitions have been developed, all having as a starting point the idea of mixing various approaches and techniques; however, for the purpose of this paper, Procter's definition was chosen as it underlines three important aspects: blended learning is not only about using different methods of delivery, but also, equally, about various teaching methods and learning styles.

The motivation behind opening up traditional teaching and learning and enriching it by means of integrating technology was largely the need to accommodate students' geographical and temporal challenges. Thus, elearning started being used either as a self-standing approach or in combination with traditional, face-to-face, teaching. It brought about the advantage of de-localisation and flexibility, allowing a departure from the "classroom paradigm" and using the virtual space as a facilitator of knowledge and information exchange [2]. However, the drawbacks of online learning became quickly apparent: the lack of social interaction and immediate feedback can lead to a decrease in the level of motivation. It is in this context that blended learning emerged, with the aim of balancing these disadvantages by combining traditional and online learning in a way that preserves the added value of both methods, adding to it the benefit of flexibility.

Blended learning is usually understood as a combination of various components. Singh distinguishes three main learning approaches that can be blended: synchronous physical formats (classroom lectures), synchronous online formats (also known as live e-learning, including virtual classrooms, webinars, web conferencing, etc) and self-paced, asynchronous formats (online training modules, simulations, recorded live events) [3]. Even though the most common case of blended learning is the mix of online and offline forms of learning, the "blend" can be seen as taking place at various levels, going beyond the method of delivery. Thus, it can refer to the combination of self-paced and collaborative online learning, but it can also designate a mix of structured and unstructured learning, acknowledging the fact that the learning process does not only occur in an institutionalized, formal environment, but also throughout day-to-day activities and contacts. Moreover, off-the-shelf and customized content can also be blended in order to better address the users' needs [3].

The underlying aspect that points towards blended learning as a viable option is the fact that learning cannot be confined in space and time, nor can it be assigned a single specific method or delivery mode. Learning is a "continuous process" [3], an "interactive dialogue" that renders each medium insufficient by itself, hence the need for blending the various media. [4] The benefits of this mix can be manifold: from optimizing the cost and time, by mixing existing resources, to being able to reach out to a larger and more diverse audience. Flexibility is one of the biggest advantages, allowing the teaching and learning process to be fully adaptable to the time schedule, previous knowledge and learning style of the user. Neverthe- 
less, this "unbounded educational discourse" [5] can only be successful if the main components of the mix are effectively integrated, following a logical and pedagogically sound structure.

By combining online and offline components, blended learning encourages the development of both equally important forms of communication: written, demanding structure and coherence, and oral, requiring spontaneity and rhetoric skills. Furthermore, it adds an extra dimension, by facilitating the creation of a "community of inquiry" [5] that brings about a reflective element as well as sense of belonging to a community. However, a very relevant aspect in a blended environment is the teaching presence that has the role of facilitating the learning experience. This can prove to be a real challenge for Higher Education institutions, as the teaching process within blended learning differs from the traditional teaching methods. The role of the teacher is no longer confined to conveying information and assessing the way it is assimilated by the students; in an online and blended environment, the teacher becomes a mediator, a facilitator, encouraging dialogue and reflective thinking rather than information storage and reproduction. This is why, in order to ensure the success of a blended learning approach, support has to be offered to both educators and students in order to understand and apply the pedagogical underpinnings of this approach [5].

Even though online learning methods have been continuously spreading in the last years in the academic community, they remain confined, to a certain extent, to natural sciences, with fewer examples from the area of social sciences. This evolution can be explained by the difference in nature between the two fields of science, the type of knowledge they involve as well as the specific skills necessary for specific disciplines. While, in the case of natural sciences, the information to be transferred is precise, and so are the results of practical exercises, in social sciences, the content is much more subjective, open to interpretation, thus requiring extensive reading and debate and, implicitly, a more flexible approach, including permanent interaction. Although e-learning systems have been addressing these issues throughout their development, allowing for a closer teacher- student and studentstudent cooperation, the social sciences students and professors are still not entirely familiarised with the online environment and tend not to use it to its full potential. Thus, e-learning spaces, even though usually highly developed, are used mainly as support material or reference tools, alongside university courses [6].

This is why a blended learning approach appears to be suitable in the field of social sciences, as it combines the online component with the more traditional face-to-face teaching and assessment methods, allowing and even facilitating the creation of a "space of learning" [7] that can benefit both the educator and the student by addressing their specific needs.

\section{BLENDED LEARNING AND EUROPEAN STUdies}

In the past decade, a multitude of academic programmes with a focus on European Studies have been created, both at graduate and post-graduate level. Furthermore, due to the relevance of EU legislation for the business but also for the non-profit sector, an impressive number of seminars and trainings have been developed, having as main target the corporate world as well as the Non-Governmental Organizations (NGOs) and other organisations whose activities have a European component.

This is the background against which the Institute of European Studies (IES), an autonomous department of the Vrije Universiteit Brussel (VUB), has developed its innovative e-learning platform, the E-Modules, designed to complement and enhance the academic offer of the Institute. That way, gradually, a blended learning approach has been embraced by drawing on the various resources available and developing a strategic outlook on how they can best be combined. The main aim is to transfer essential and constantly updated information about the European Union, in a user-friendly manner that brings together thorough academic knowledge and accessible and flexible modes of delivery.

\section{A. Why blended learning? Concept and components}

In a rather uncommon sequence of events, the starting point was not the traditional "classroom method", but the E-Modules, the online learning platform. Initially conceived as an independent learning tool, the E-Modules profiled themselves as a provider of essential and concise information on the various aspects of the European Union, compiled in a clear way and accessible at any time and from anywhere. The challenges faced by the platform were linked to both the technological developments and the constantly changing environment of the European Union that require continuous updates of content and interface. Moreover, one of the main issues that had to be taken into account was ensuring the interactive component in order to keep up the level of motivation of the users.

Gradually, the idea of complementing the online courses with face-to-face sessions became one of the most obvious and viable ways of enhancing interactivity. Short "classroom sessions" at the beginning of the course were perceived as a means of creating a "learning community" feeling, a very important aspect for the efficiency of online learning. In time, the rather ad-hoc face-to-face sessions were transformed into one to three days training seminars, strategically designed to complement the use of the e-learning platform.

Furthermore, while striving to reach out to a geographically and professionally diverse audience, it appeared relevant to develop means of synchronous interaction that are not confined to a physical space and can benefit the users in a very flexible manner. The use of "virtual office hours" (VO), online (video) chat sessions and online seminars (webinars) came as a welcome addition to the EModules and the traditional training seminars, enhancing the interactivity factor and combining it with the advantages of the virtual environment.

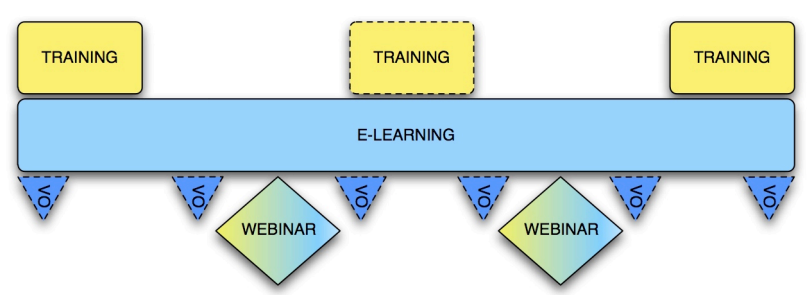

Figure 1. The European studies blended learning continuum 
PAPER

The simultaneous use of the three blended learning components (Figure 1) is proving to be helpful in attaining the initial goals of our pedagogical activity. However, special attention needs to be paid to make sure that the blending takes place in a well-structured manner, where each teaching and learning approach is used to answer specific needs.

\section{B. E-Modules: the e-learning platform}

The E-Modules are the first and main component of the blended learning approach of the IES. The objective of EModules as an online learning tool is to offer a structured and interactive way of getting acquainted with the history of the European Union, its structure, policy areas, decision-making process, law, etc. The European Union is a very intricate, constantly developing and changing international actor, and a large number of information sources covering this topic exist. The challenge in this respect for persons interested in the European Union is to find their way through the large amount of information available and to understand the meaning of many terms specifically used in the context of European integration. In this regard, the modules offer easily comprehensible, free of EUjargon, well structured information, which allows the users to develop a basic understanding of what the European Union is about and how it functions and then have the option of enhancing their knowledge by concentrating in-depth on more specific topics.

The online learning platform currently consists of three modules: the module on European History, Institutions and Decision Making, the module on European Union Law and the module on European Information Sources. Nevertheless, the Institute currently works on expanding the areas covered by the e-learning tool by creating new modules that deal in a more in-depth manner with specific policies of the European Union like, for instance, Environmental Policy, European Foreign and Security Policy, etc. The first module on European History, Institutions and Decision Making provides an overview of the history of post-war European integration. It introduces the students to the foundations of the European Union in the form of the founding treaties, deals with the various institutions, bodies and agencies of the European Union and describes and analyses the decision making on the European level including the various procedures employed in the process. The module on European law concentrates on the legal perspective by dealing with the characteristics, principles, objectives and sources of European Union law and the various policies of the European Union including the European Foreign and Security Policy and the Police and Judicial Cooperation in Criminal Matters. The third module addresses the challenge of finding the right information on European Union matters like, for instance, background information, legal acts, policy documents, etc. taking into consideration that a vast majority of complex information sources on the topic exist and that specific background knowledge is required on certain occasions to get access to the information needed. Therefore, the third module gives the students an overview of available EU information sources and trains their skills of EU information retrieval.

The E-Modules consist of a knowledge/theoretical component combined with a practical component comprising case studies, real-life scenarios, EU case law, practical examples from the day-to-day work of the insti- tutions and exercises. The aim in this regard is to make the topics covered more tangible and easily accessible for the students. The e-learning tool has a user-friendly interface, which allows the students to control the learning process by providing information on the content of each chapter in the form of a brief description of the topics covered, a definition of the learning targets at the beginning of every chapter and information on what parts of the modules were already covered. Furthermore, the e-learning tool offers a wide number of exercises allowing the practical application of the newly acquired knowledge. In addition to the main pages, the modules also contain so-called "nice to know pages" which complement the main pages by providing additional, more in-depth information to certain aspects of the topics covered. The "nice-to-knowpages" contain the text of relevant articles from the Treaties, tables, pictures, graphics, maps, biographical notes, etc.

It is of crucial importance for an online learning system to provide tools for self-assessment of the progress made and self-evaluation. The E-Modules offer such tools in the form of a system of page tests and chapter tests which allow the students to determine the level of knowledge and skills acquired so far as well as the areas that require further work. The test system of the E-Modules encompasses multiple choice questions as well as open answer questions, and the students receive feedback on the test automatically after it has been submitted. In order to support the constant self-evaluation process, the students can repeat the tests unlimited number of times. In addition, the students have the possibility to complete the modules with a face-to-face exam in Brussels and receive a respective certificate. As a preparation for this final exam, the students have access to comprehensive online tests on every module, which simulate the face-to-face exam in Brussels.

\section{Face-to-face training}

The second component of the blended learning approach of the IES is the face-to-face training, which takes place in the form of three-day intensive training sessions explaining the essentials of the European Union and providing an advanced understanding of the EU institutions and the decision-making process. The face-to-face training sessions cover a wide number of topics like history and institutional structure of the EU, the role and competences of Council, Commission, Parliament and European Court of Justice as well as the process passing legislation on EU level, different policy areas of the EU like the European Foreign and Security Policy and Justice and Home Affairs, EU information sources, etc. In essence, the face-to-face training sessions cover the most important topics of the E-Modules, but in a more intense and indepth manner and are used to complement the online learning process. In addition, the in-house training contains further topics not addressed at length in the modules like the comitology procedures, interest representation and lobbying, alternatives to the so-called community method, etc. As the E-Modules, the IES training concept promotes a balanced approach, where theory and practice complement each other to facilitate the learning experience, and, therefore, accomplished academics and practitioners conduct the in-house training. Every topic is covered in a comprehensive manner with the use of practical examples, case studies, dossiers, etc. The aim of the in-house training sessions is not the one-way transmittance of knowledge, 
PAPER

but the creation of an atmosphere for the facilitation of a dialogue with the students. Comprehensive study materials and additional literature supplement the presentations on every topic.

The number of participants for each training session is limited so that the learning process can take place in a small group of students (between 10 and 12) in order to create a "learning community" feeling and facilitate interaction and debate between the group members on the one hand and the students and the teacher on the other hand. Experience shows that small groups are much more effective in pedagogical terms, regarding the learning outcome and the creation of a group identity. Moreover, the added value of these training sessions is not only the transmittance of knowledge, but also the motivation of students, who otherwise work on their own and feel growing isolation in the online working environment as well as the exchange of learning experiences and information. The face-to-face environment is the opportunity for all students to take part actively in the debate so crucial for teaching social sciences and to receive answers to questions they have encountered while studying the subject matter.

\section{Webinars: online synchronous interaction}

The latest addition to the European Studies "blend" is the use of synchronous online interaction tools. As the courses evolved from a simple online platform, with few elements of interactivity, to a mix between online and face-to-face methods, it became apparent that the missing link was an online interactive component. That was thought to enhance the engagement of the learners and to keep their motivation at a high level in between (or in the absence of) face-to-face sessions. Moreover, it makes it possible to enlarge the audience the courses are addressed to, rendering interaction independent of location and flexible in terms of timing.

The synchronous online interaction takes place at various levels and fulfills specific pedagogical goals. First of all, "virtual office hours" (VO in Figure 1) are made available to the users on a regular basis throughout the duration of the course. They are aimed at facilitating communication between the learners and the educators, complementing the email exchange with a real time conversation in the form of written chat or video/ audio conferencing. The "virtual office hours" are used for providing introduction and support with both the technical issues of using the online platform and the content. Keeping a versatile format is the key to maximizing the use of the tool. Thus, interaction takes place through one to one or group discussions, is structured around a pre-determined topic or is of a rather unstructured, spontaneous nature. Whichever the form, the essential idea behind having a "virtual office" is offering the users, both teachers and learners, a space for direct communication. Whereas in the case of traditional education, direct contact is a given, in the case of online or blended learning, special efforts have to be made to create and maintain a sense of community, including constantly available support, which is very important for the learning process to fulfill its goals.

Secondly, the online conferencing facilities are used to organize short seminars (two to three hours) on specific institutional or policy aspects of the European Union. These webinars (Figure 1) are designed to complement the material available on the online platform, of a rather gen- eral, overarching nature, going into more details in specialized areas. They are also meant to focus on certain issues that are not covered in-depth in the face-to-face training sessions, due to time constraints. The main benefit of the webinars is flexibility. They can be customized to fit the specific needs and interests of the learners, allowing them to take part from wherever they are and therefore being easier to integrate in their daily schedule. Moreover, alongside the regular tutors, external speakers, academics as well as policy makers, specialized in the topics being discussed, are able to participate and give their input, irrespective of their location and without the costs and time involved by traveling. This is a vital aspect for a course in European studies, in an environment where an overwhelming amount of information is freely available, as it brings added value and at the same time creates an 'event' element by offering a forum of debate and experience sharing for people studying and/or working in the same field in various locations. Webinars make knowledge and expertise more easily accessible, with geographical borders, disciplinary borders, but also the traditional teacher/ student border becoming irrelevant within a common "learning space".

With the advantages of flexibility and versatility, the use of online synchronous interaction has brought the overall course to a higher level, by improving the communication among all actors involved, enriching the content as well as making it more accessible to a larger audience. However, it soon became apparent that the use of such tools, even more than the e-learning platform, requires specific skills from the side of the educators, skills that are not necessary in the traditional educational process. The absence of physical contact with the audience, the need for more clarity in the written and verbal discourse, all require a special effort and a high level of openness towards the benefits of using technology in education. Understanding and embracing the different pedagogical aspects on synchronous online interaction may require specific training, but in the long run, for reaching the aims and the target audience of the courses in European studies, webinars as well as "virtual office hours" are two of the key elements that need to be developed.

\section{CONCLUSIONS: FINDING THE Right BLEND}

After looking into the three main components of the blended learning approach used in the IES European Studies programme, it is important to analyze the way they work together and determine what the main challenges for the future are. The gradual approach, in which the "blend" came into being, implies, on the one hand, that the development was driven by the needs identified on the relevant market, as the newly added elements were designed to complement the existing ones by addressing their shortcomings. On the other hand, the step-by-step basis also reveals the fact that an overall strategy for the blended learning approach as such had not been created from the start, but has been augmented in the course of creation priority being given to each specific method used at the time. One of the most important aspects, and indeed one of the main challenges, is to define the place of each medium according to its specific functionalities. Blended learning involves bringing together pre-existing resources as well as creating new ones, but the crucial underlying goal is that the final product represents more than the sum of its parts. The added value in the case of European stud- 
ies is that by using the blend of online and face-to-face methods the course can reach a larger target audience, from various locations and, at the same time, access to knowledge and expertise in the field (general European issues and different policy areas) is facilitated by using a virtual learning and interaction platform. Through the blending of different teaching methods, the shortcomings of each one of them have been eliminated to enhance the pedagogical results of the course as much as possible.

Given the specificities of the European studies area and its multidisciplinary character and taking into account the broad audience spectrum the course is addressing (from students to professionals working with European Union related issues), a mix of delivery methods as well as teaching modes and learning styles appears to be the most suitable approach. The multifaceted nature of the subject area in conjunction with the diversity of backgrounds and interest of the learners make the case for a personalization of the learning experience. This translates into a learnercentered approach, providing flexibility to choose the most relevant parts of the content and the most suitable delivery mode. However, this points towards a self-pace learning style, which, in its turn, has to be balanced with the interactive element. Allowing learners to be in charge of creating their own "blend" while, at the same time, trying to build a "learning community" that goes beyond (and can do without) the classroom is a challenge that has to be addressed in order to ensure the success of blended learning.

Embracing a new pedagogical approach involves a process of re-thinking of priorities at various levels, from the management and administrative level to the delivery of the course content. Blended learning implies a mix of methods and, therefore, a departure from traditional teaching. This requires first and foremost a thorough structure and planning. Clear organization is a key element for ensuring that the various educational activities are pursued coherently; more flexibility for the learners translates into a more complex student administration system and its efficient management is vital for the success of this approach. Moreover, especially in the case of online methods, both synchronous and self-paced, educators need specific skills to manage the pedagogical activities in a virtual environment. A "train the trainer" policy, alongside constant technical support, is of crucial importance for maintaining a high level of academic content in a smoothly running online/offline environment.
The use of the blended learning approach in the European studies course has proved to be beneficial for both educators and learners. The flexibility it offers, together with the aim of creating a "learning community", appears to be suitable to the complexity of the subject matter and the diversity of the audience. Bringing together educational resources of different nature in a logical and strategic manner, the resulting "blend" is more valuable from a pedagogical point of view than each of the composing methods by itself. The main added value rests in designing a learning experience that puts the learners in control while offering them the opportunity to interact with their pairs and educators in a flexible yet meaningful way, irrespective of their background and location.

\section{REFERENCES}

[1] Procter, C., (2003) "Blended Learning in Practice", In Inaugural Education in a Changing Environment conference University of Salford, Salford, UK

[2] Mihai, A., (2009) "Teaching European Studies Online: The Challenge of Quality Assurance", In European Journal of Open, \begin{tabular}{l} 
Distance and E-learning, [online], \\
\hline
\end{tabular} http://www.eurodl.org/?article $=377$

[3] Singh, H., (2003) "Building Effective Blended Learning Programs", In Educational Technology, Volume 43, Number 6, p. 5154

[4] Heinze, A., Procter, C., (2004) "Reflections on the use of blended learning", In: Education in a Changing Environment, 13-14 September 2004, University of Salford, UK

[5] Garrison, R., Kanuka, H., (2004) "Blended learning: Uncovering its transformative potential in higher education", In Internet and Higher Education 7, p. 95-105. http://dx.doi.org/10.1016/ j.iheduc.2004.02.001

[6] Budka, P., Mader, E., (2006) "E-learning in the social sciences: experiences with creating communities, networks and strategies", paper read at the conference Learning Communities, Klagenfurt, Austria, 9-11 November 2006

[7] Oliver, M., Trigwell, K., (2005) "Can 'Blended Learning' Be Redeemed?", In E-Learning, Volume 2, Number 1, p. 17-26. http://dx.doi.org/10.2304/elea.2005.2.1.2

\section{AUTHORS}

A. Christova (e-mail: alina.christova@,vub.ac.be) and A. Mihai (e-mail: alexandra.mihai@vub.ac.be) are with the Institute for European Studies in Brussels, Belgium.

Received 28 July 2011. Published as resubmitted by the authors 22 November 2011. 